\title{
SISTEMAS POLÍTICOS NA AMÉRICA DO SUL NO CONTEXTO DA “MARÉ ROSA": DEMOCRACIA, ESTABILIDADE E GOVERNANÇA NO SÉCULO XXI ${ }^{12}$
}

Lucas Cunha ${ }^{3}$

Victor Araújo ${ }^{4}$

\section{Resumo}

Este trabalho discute a natureza das esquerdas que ascenderam ao poder na América do Sul desde o final dos anos 1990 e as suas implicações para a estabilidade e os padrões de governança na região. A partir da análise de 13 governos em 8 países - Argentina, Bolívia, Brasil, Chile, Equador, Paraguai, Uruguai e Venezuela - discutimos em que medida a dimensão da estabilidade é uma condição suficiente no que tange à capacidade das democracias sul-americanas adotarem políticas que promovam desenvolvimento econômico e social. A principal hipótese deste trabalho é que a percepção da estabilidade está relacionada com o nível de estruturação do sistema partidário. Os resultados indicam que 1) estabilidade política varia conforme o nível de estruturação dos sistemas partidários e 2) não obstante o primeiro resultado, estabilidade política não é uma condição suficiente para a governança democrática, posto que mesmo nos países de menor estabilidade política os governos de esquerda tem sido hábeis na implementação de políticas - aumento das taxas de crescimento da economia, aumento do gasto social, aumento do IDH, redução da pobreza extrema e redução da taxa de desemprego - que melhoram as condições de vida da população.

Palavras - Chave: América do Sul, Maré Rosa, Estabilidade Política, Sistemas Partidários.

\begin{abstract}
This paper discusses the attributes of leftists who access to power in South America since the late 1990s and its implications for the stability and governance standards in the region. From the analysis of 13 governments in 8 countries - Argentina, Bolivia, Brazil, Chile, Ecuador, Paraguay, Uruguay and Venezuela - we discuss to what extent the size of stability is a sufficient condition in relation to the capacity of South democracies American adopt policies that promote economic and social development. The main hypothesis is that the perception of stability is related to the level of structure of the party system. The results indicate that 1) political stability varies with the level of structure of party systems and 2), although the first result, political stability is not a sufficient condition for democratic governance, since even in countries with less political stability of governments left has been able to implement policies - higher growth rates of the economy, increase in social spending, increase the HDI, reducing extreme poverty and reducing the unemployment rate - that improve the living conditions of the population.
\end{abstract}

Key-Words: South America, Pink Tide, Political Stability, Party-Systems.

\section{Resumen}

Este trabajo analiza los atributos de la izquierda que llegó al poder en América del Sur desde finales de 1990 y sus implicaciones para la estabilidad política y gobernabilidad en la región. A partir del análisis de 13 gobiernos en 8 países - Argentina, Bolivia, Brasil, Chile, Ecuador, Paraguay, Uruguay y Venezuela - donde discutimos en qué medida la estabilidad de la dimensión es una condición suficiente, en relación con la capacidad de las democracias del Sur Americana adoptar políticas que promuevan el desarrollo económico y social. La hipótesis principal es que la percepción de la

${ }^{1}$ DOI deste artigo: http://dx.doi.org/10.5380/recp.v5i2.37501

2 Agradecemos ao Professor Carlos Moreira (Universidad Autónoma de Baja California, México) pela leitura da primeira versão do trabalho na ocasião do $23^{\circ}$ Congresso da Associação Internacional de Ciência Política (IPSA), bem como ao parecerista anônimo da Revista Eletrônica de Ciência Política pelas sugestões que resultaram na versão final do trabalho.

${ }^{3}$ Doutorando em Ciência Política na Universidade Federal de Minas Gerais e Pesquisador do Centro de Estudos Legislativos (CEL/UFMG).

${ }^{4}$ Mestrando em Ciência Política na Universidade de São Paulo. 
estabilidad está relacionada con el nivel de organización del sistema de partidos. Los resultados indican que 1) la estabilidad política varía con el nivel de la estructura de los sistemas de partidos y 2) a pesar del primer resultado, la estabilidad política no es una condición suficiente para la gobernabilidad democrática, ya que incluso en los países con gobiernos políticos menos estables la izquierda ha sido capaz de implementar políticas - aumentar las tasas de crecimiento de la economía, el aumento de los gastos sociales, aumentar el índice de desarrollo humano, la reducción de la pobreza extrema y la reducción del desempleo - que mejoran las condiciones de vida de la población.

Palabras-clave: América del Sul, Marea rosa, Estabilidad Política, Sistemas de Partidos

\section{INTRODUÇÃO}

Democracias, de um modo geral, se institucionalizam através do jogo democrático com eleições periódicas, limpas e livres, e com incentivos à ampliação de mecanismos de participação política. A suposição é que a competição eleitoral produz condições para institucionalização e estabilização de uma das importantes variáveis relacionada ao jogo democrático: o sistema partidário. Esta variável é fundamental para a compreensão do grau de competição de um dado sistema político e a sua institucionalização está relacionada ao processo de estabilidade dos governos constituídos em regimes democráticos (Przeworski, 1991).

Neste trabalho assumimos que diferentes tipos de esquerdas estão ligadas a diferentes ambientes institucionais e à própria organização democrática dos casos analisados. Tais ambientes condicionam, entre outras coisas, o nível de estruturação dos sistemas partidários. Nesse sentido, tentaremos argumentar que há uma associação entre o tipo de esquerda que ascendeu ao poder e o nível de estruturação do sistema partidário nos casos analisados.

Um argumento amplamente difundido na ciência política é o de que as condições de institucionalização dos sistemas partidários importam para o bom funcionamento da democracia (Mainwaring e Scully, 1997; Mainwaring e Torcal, 2005; Melo, 2015). Nesse sentido, o grau de institucionalização dos sistemas partidários - doravante também denominado nível de estruturação dos sistemas partidários - tem sido apontado como um dos fatores determinantes da estabilidade política nos arranjos democráticos, uma vez que influencia tanto os vínculos entre eleitores e partidos, quanto a confiança nos regimes democráticos. No entanto, se é verdade que as condições de estruturação dos sistemas partidários impactam a estabilidade das instituições que dão sustentação aos sistemas políticos, não estão claras as implicações da variação da estabilidade nas democracias contemporâneas. 
No que diz respeito às democracias latino-americanas, a baixa institucionalização dos sistemas partidários dessa região têm sido utilizada para postular uma hipotética incapacidade dessas democracias para produzir processos institucionais de qualidade e, como consequência, incapacidade de implementarem políticas abrangentes capazes de melhorar as condições de vida dos seus cidadãos (Mainwaring; Scully, 2008).

Sob este prima, o objetivo deste trabalho é discutir a seguinte questão: democracias pouco estáveis são incapazes de promover o desenvolvimento político, econômico e social? Diferentemente do que tem sido apontado por parte da literatura (Castañeda, 2006), a despeito da baixa estabilidade política encontrada em alguns países da região, no período recente a América Latina se destaca entre as poucas regiões do mundo que conseguiram alcançar a melhoria dos seus indicadores sociais por via da democracia (Huber; Stephens, 2012). Em termos mais precisos, na contramão dos Estados Unidos e Europa e ao contrário do que muitas teorias previam, os países da América Latina se destacam pela redução de desigualdade e pobreza no século XXI (Piketty, 2014).

Portanto, o argumento de que democracias com baixa estabilidade política não são capazes de promover desenvolvimento econômico e social não se sustenta empiricamente. Como mostraremos nesse trabalho, no contexto sul-americano, mesmo nos países menos estáveis, indicadores como o PIB per capita, redução da população vivendo com menos de dois dólares por dia, aumento do IDH e redução da taxa de desemprego apresentam uma tendência de melhora constante nas últimas três décadas. Ademais, argumentamos que a melhoria desses indicadores sociais não é um processo aleatório e descoordenado, mas resultado do aumento dos gastos sociais alcançado, sobretudo, desde que no final do século XX quando uma série de partidos de esquerda alcançou o poder na América Latina.

Além dessa introdução, na segunda parte, discutiremos a natureza das diferentes esquerdas emergentes na América do Sul no contexto da Maré Rosa. Na terceira parte, lançamos o debate acerca da natureza das esquerdas que ascenderam ao poder na região e as mudanças nas "regras do jogo". Posteriormente, na quarta parte, através da apresentação de indicadores sociais e econômicos, discutiremos em que medida a variável estabilidade é uma condição suficiente no que tange à capacidade das democracias sul-americanas adotarem políticas que promovam desenvolvimento econômico e social. Por fim, na última parte, concluímos e realizamos apontamentos. 


\section{2. "MARÉ ROSA" NA AMÉRICA DO SUL: DE QUANTAS E QUAIS ESQUERDAS ESTAMOS FALANDO?}

Como resultado da insatisfação com as políticas pró-mercado implementadas nos anos 1980 e 1990 (SELIGSON, 2007; MADRID, 2010; NUNES, 2014), a virada às esquerdas - ou "maré rosa" das esquerdas (LIEVESLEY e LUDLAM, 2009) - que atingiu a América Latina representou um novo alinhamento das agendas políticas propostas pelos presidentes eleitos.

A alternância ideológica promovida na América Latina despertou um novo debate acerca de seus discursos e agendas políticas. Novos procedimentos democráticos começaram a ser utilizados por esses governos eleitos, que passaram a implementar políticas mais efetivas de combate à desigualdade e pobreza (LA TORRE, 2013), medidas de realinhamento da política econômica, mudanças na condução da política externa - a partir de uma nova política de cooperação regional e maior autonomia em relação à diplomacia dos Estados Unidos -, além da inclusão de novos mecanismos de participação direta (ALTMAN, 2010).

No entanto, com a ascensão de tipos distintos de esquerda ao poder, surge uma questão controversa sobre como classificar a heterogeneidade de plataformas políticas desses governos eleitos, uma vez que esse cenário possui uma grande diversidade entre os países analisados na América do Sul (Quadro 1).

Propomos aqui uma classificação que leva em conta as plataformas políticas da esquerda eleita em termos da sua relação com o sistema político, econômico e social (esquerda sistêmica e antissistêmica) e a estruturação do sistema partidário como proxy da estabilidade política na região.

\footnotetext{
${ }^{5}$ O termo foi utilizado pela primeira vez pelo jornalismo político, no ano de 2005 após a vitória de Tabaré Vasquez no Uruguai para denotar a cor associada à esquerda, o vermelho, mas numa versão mais moderada do comunismo que se tornou por sua vez cor-de-rosa, desse modo não seria uma onda vermelha, mas sim uma onda maré ou rosa mais ver: http://www.nytimes.com/2005/03/01/international/americas/01uruguay.html? r=0
} 
QUADRO 1: ESQUERDAS NO PODER NA AMÉRICA DO SUL NO INÍCIO DO SÉCULO XXI

\begin{tabular}{|c|c|c|c|}
\hline País & Presidente & Partido do Presidente & Período \\
\hline \multirow[t]{2}{*}{ Brasil $^{6}$} & Luiz Inácio Lula da Silva & PT & $(2003-2010)$ \\
\hline & Dilma Rousseff & PT & (2011-atual) \\
\hline \multirow[t]{2}{*}{ Uruguai $^{7}$} & Tabaré Vasquez & Frente Amplio & $(2005-2010)$ \\
\hline & José Mujica & Frente Amplio & (2010-2015) \\
\hline \multirow[t]{2}{*}{ Chile } & Ricardo Lagos & PSCH (Concertación) & $(2000-2006)$ \\
\hline & Michelle Bachelet & PSCH (Concertación) & $(2006-2010)$ \\
\hline Bolívia & Evo Morales & MAS-IPSP & (2006-atual) \\
\hline Venezuela & Hugo Chávez & PSUV & $(1999-2013)$ \\
\hline Equador & Rafael Corrêa & Alianza PAIS & (2006-atual) \\
\hline \multirow[t]{2}{*}{ Argentina } & Nestor Kirchner & PJ & (2003-2007) \\
\hline & Cristina Kirchner & PJ & (2007-atual) \\
\hline Paraguai & Fernando Lugo & Frente Guasú & $(2008-2012)$ \\
\hline
\end{tabular}

Fonte: Elaboração própria

Desse modo, pode haver em alguns casos um sistema partidário estruturado e noutros um sistema partidário não estruturado, denotando de uma maneira geral um sistema político mais ou menos estável conforme essas variáveis. A opção por tornar dicotômica a classificação dos sistemas partidários tem o objetivo de facilitar a construção de uma tipologia das esquerdas e dos sistemas partidários, de modo a relacionar esta dimensão à estabilidade política verificada nos casos analisados. Em alguns países a instabilidade política se mantém elevada, como no caso da Venezuela, em outros o contexto democrático é estável sem maiores sobressaltos para o jogo democrático, como é o caso do Chile ou do Uruguai.

\footnotetext{
${ }^{6}$ O segundo mandato (2015-2018) da Presidente Dilma Rousseff não foi contemplado na presente análise.

${ }^{7}$ O segundo mandato (2015-2019) do Presidente Tabaré Vasquez não foi contemplado na presente análise.
} 
Se por um lado a literatura identifica uma esquerda moderada ou sistêmica (Castañeda, 2006; Madrid, 2010), como por exemplo, no Brasil, Chile e Uruguai, há também casos em que a esquerda é, frequentemente, acusada de ter um caráter neopopulista por suas plataformas de refundação das bases da legitimidade do Estado. Enquadram-se nessa última caracterização os governos de Hugo Chávez e Nicolás Maduro, que alteraram a ideia de legitimidade do Estado venezuelano sob a égide do bolivarianismo ${ }^{8}$, Rafael Corrêa no Equador e Evo Morales na Bolívia ${ }^{9}$.

De modo a retirar o caráter normativo do termo neopopulista, ou esquerda certa ou errada nos termos de Castañeda (2006), optou-se aqui por chamar a dita esquerda socialdemocrata de esquerda sistêmica, dado que esta não rompeu com o legado do passado nos países analisados. E, na outra direção, optou-se por chamar de esquerda antissistêmica pelo seu caráter de reforma das instituições existentes. Nos casos em questão (Bolívia, Equador e Venezuela), a esquerda é acusada de ser neopopulista, principalmente pela precariedade e normatividade conceitual do termo populismo e da discussão relacionada a ele na América Latina ${ }^{10}$.

Análises recentes da alternância ideológica na América do Sul utilizam distintos qualificativos para estas esquerdas, quais sejam: esquerda contestatória (Madrid, 2008), esquerda anti-capitalista, esquerda intervencionista e esquerda neopopulista por um lado e, por outro lado, esquerda social-democrata, esquerda moderada, esquerda "light", esquerda capitalista e esquerda sistêmica. Não obstante essas classificações serem um tanto quanto

\footnotetext{
8 A ideia de bolivarianismo é inspirada na liderança do político e militar venezuelano Simon Bolívar considerado um herói da independência ainda no século XIX. De acordo com Belém Lopes (2013) o bolivarianismo de Simon Bolívar, ou bolivarianismo original remete à mescla de republicanismo aristocrático do Oitocentos com o desejo de reprimir as convulsões domésticas da Venezuela no período. O a expressão bolivarianismo foi cunhada, ainda de acordo com Belém Lopes (2013) pelo general Eleázar López Contreras, em discurso no qual dizia que a inspiração seu governo era em ideais bolivarianos. Isso quer dizer que no sentido original, não havia conotação de esquerda no termo bolivarianismo. No significado dado pelo governo Chávez ao bolivarianismo este possui uma conotação de justiça social associada à plataforma socialista. Houve no período, de acordo com Buxton (2009), uma significativa redistribuição do poder político e econômico de uma elite minoritária para uma maioria politicamente excluída e economicamente marginalizada. O bolivarianismo sob o comando de Chávez redefiniu a narrativa política regional introduzindo uma nova linguagem de cidadania, participação, orgulho cultural e soberania.

9 Para mais sobre a diferenciação entre a esquerda social-democrata e a esquerda neopopulista, ver Jorge Castañeda, (2006) “Latin America’s Left Turn".

10 De acordo com Mitre (2009) o termo populismo é esvaziado de valor heurístico que lhe atribuíram o marxismo e a sociologia da modernização, dissociado de qualquer referência a um período específico ou a um sistema em particular. Nas palavras do próprio autor: "Uma vez que o populismo, (...) assumiu a condição de síndrome sem relação com o sistema social, e sua causa passou a se alojar no temperamento afoito de algumas lideranças, ficou expedito 'o caminho para a formulação da hipótese neopopulista' A partir de então, alguns regimes neoliberais, antípodas em quase tudo da orientação característica do populismo clássico, passaram a ser considerados rebentos da mesma cepa em função de traços isolados e pontuais: práticas clientelísticas, personalismo, políticas assistencialistas de alcance restrito e dirigidas a paliar os efeitos perversos das reformas econômicas dos anos 1980 e 90. Convertido em adjetivo sem coloração ideológica definida, mas impregnado de conotações pejorativas, o termo populista começou a ser aplicado, então, indistintamente a governos de direita ou de esquerda." (pp.12)
} 
arbitrárias, elas possibilitam que seja estabelecida uma distinção entre diferentes plataformas políticas e indicam a existência de diferenças significativas nas agendas políticas dos presidentes eleitos no que diz respeito à preservação ou não do legado do passado político recente.

\section{IDENTIFICAÇÃO PARTIDÁRIA, ESQUERDAS NO PODER E MUDANÇA NAS “REGRAS DO JOGO”: TRÊS DIMENSÕES DA POLÍTICA SUL- AMERICANA RECENTE}

Desde o fim dos anos de 1990, observa-se na América do Sul processos constitucionais ou revisões das regras políticas que alteraram o edifício institucional da região. Tais mudanças se diferem na sua condução e no seu conteúdo; há desde pequenas reformas eleitorais e inclusão de novos programas sociais (Brasil sob o governo Luíz Inácio da Silva, Uruguai com Tabaré Vasquez e José Mujica, e Chile com Ricardo Lagos e Michelle Bachelet) até processos constitucionais radicais (Venezuela com Hugo Chávez, Bolívia com Evo Morales, e Rafael Correa no Equador). Tais mudanças interferem - de maneiras distintas - no modelo clássico de democracia representativa e possuem consequências ainda não consensualmente discutidas por analistas.

Nos casos de Venezuela, Equador e Bolívia, algumas abordagens chegam a questionar inclusive o caráter democrático desses regimes, considerando que estes já não figuram na família dos regimes democráticos e teriam decaído para a categoria de semidemocracias, democracias parciais, democracias virtuais, democracias iliberais, semiautoritarismos ou ainda soft authoritarianisms. De toda maneira, esses novos regimes podem ser considerados, nos termos de Diamond (2002) e Morlino (2008) como "híbridos", ou seja, regimes que mesclam elementos autoritários e democráticos.

Em outros termos, esses novos regimes seriam uma espécie de autoritarismos competitivos (Levitsky; Way, 2002). Há ainda a consideração de Gereffi et al (2007), que enquadram estes casos na categoria dos países de consolidação democrática incompleta, ou seja, aqueles processos de redemocratização nos quais ao lado das instituições democráticas também se consolidam instituições autoritárias, de modo que nesses regimes não existiria a possibilidade - pelo menos em tese - de um retorno ao autoritarismo, mas também a consolidação da democracia se mostra incompleta.

Para Madrid (2010), a esquerda liberal (ou sistêmica nos termos aqui propostos) é composta por partidos relativamente bem institucionalizados e a esquerda intervencionista 
(ou antissistêmicas nos termos aqui propostos) consiste em movimentos novos, fluidos e altamente personalistas. Um exemplo típico desses movimentos pode ser identificado no MAS na Bolívia, que se constitui como um partido-movimento com baixíssimo grau de institucionalização, pelo PSUV na Venezuela, criado por Hugo Chávez, e o Alianza PAIS capitaneado por Rafael Correa no Equador, casos que se afastam da ideia de partidos políticos no sentido clássico do termo.

No caso das esquerdas sistêmicas, os atores políticos que se sagraram vitoriosos no início do século XXI já existiam no campo das oposições na década de 1990 e têm graus de institucionalização mais elevados. Precisaram migrar para o centro ou compor coalizões com partidos fora do campo das esquerdas a fim de vencer eleições, esse foi o caso do PT no Brasil. Assim, as esquerdas sistêmicas chegaram ao poder em contextos em que a população já havia sido beneficiada com a estabilização inflacionária, impedindo que estas esquerdas rompessem completamente com as mudanças econômicas implementadas nos anos 1990. Dito de outro modo, no caso das esquerdas antissistêmicas, foi possível a proposição de uma agenda de mudança radical dos rumos políticos diante do fracasso das reformas pró-mercado nesses países.

Lanzaro (2007) denominou esse processo de "terceira onda das esquerdas na América Latina", havendo desde reformas comprometidas com o modelo representativo clássico (Brasil, Chile e Uruguai), até presidentes dispostos a transformar profundamente as bases de legitimidade dos Estados (Bolívia, Venezuela e Equador). O quadro abaixo tenta sumarizar essas diferentes esquerdas na América do Sul e sua relação com o sistema partidário $^{11}$.

Este trabalho propõe a análise das esquerdas sul-americanas a partir de dois eixos analíticos que se correspondem e, no nosso entendimento, explicam parte do contexto de baixa estabilidade da região. Um primeiro eixo enquadra os países estudados em duas dimensões do sistema partidário, (a) Estruturado e (b) Não estruturado.

\footnotetext{
${ }^{11}$ Essa tipologia é proposta por nós com base nas plataformas políticas implementadas por esses governos e pelo grau de estruturação do sistema partidário.
} 


\section{QUADRO 2: TIPOLOGIA DAS ESQUERDAS E DOS SISTEMAS PARTIDÁRIOS NA}

AMÉRICA DO SUL

\begin{tabular}{|c|c|c|c|}
\hline \multicolumn{2}{|c|}{} & \multicolumn{2}{c|}{ Tipo de Esquerda } \\
\cline { 3 - 4 } & \multirow{3}{*}{ Sistema } & Sistêmica & Antissistêmica \\
\cline { 3 - 4 } Partidário & & Uruguai & - \\
& & Chile & \\
\cline { 3 - 4 } & Não & Brasil & Equador \\
& estruturado & Argentina & Venezuela \\
& & Paraguai & Bolívia \\
\hline
\end{tabular}

Fonte: Elaboração Própria

Está divisão se assenta sob o argumento de que os sistemas partidários podem ser separados enquanto estáveis e institucionalizados (a) e, do outro lado, fluídos e pouco institucionalizados (b). O segundo eixo enquadra os países analisados no que diz respeito aos tipos de esquerda que ascenderam ao poder desde o final da década de 1990. São separados os governos oriundos de uma esquerda sistêmica daqueles países onde as esquerdas podem ser caracterizadas como antissistêmicas. Denominamos esquerda sistêmica aqueles casos onde o partido (ou coalizão) de esquerda, uma vez no poder, não rompeu com o legado liberal de economia e o formato clássico de democracia representativa. Contrariamente, partidos de esquerda (ou coalizão) com uma tendência antissistêmica possuem como características principais a aversão às tendências neoliberais de condução da economia e uma forte inclinação para a intervenção do estado na economia. Nós argumentamos que a combinação desses dois fatores associados explica parte da pouca estabilidade revelada em alguns países da América do Sul.

Nesse enquadramento, a desestruturação do sistema de partidos não é oriunda da alternância ideológica recente, mas a chegada desses atores ao poder agravou os sistemas partidários já fortemente desestabilizados. Vale lembrar que o processo de ascensão de tipos distintos de esquerdas não ocorreu imediatamente após o fim dos regimes militares e está ligado aos resultados produzidos pelas decisões tomadas pelas elites políticas que governaram no período imediatamente posterior aos governos militares.

Após a transição para a democracia houve um período (início da década dos anos 1990) de ascensão de presidentes com plataformas políticas mais claramente identificadas 
com os preceitos do chamado Consenso de Washington ${ }^{12}$, também identificadas com aquilo que se denominou de neoliberalismo. Menem na Argentina e Collor no Brasil, por exemplo, promoveram reformas pró-mercado no início dos anos 1990 com consequências distintas para a economia de cada um desses países. Verifica-se que houve uma continuidade na plataforma política no Brasil, Chile e Uruguai, casos onde os presidentes não romperam com o legado do passado. Nos casos de Bolívia, Equador e Venezuela, os péssimos resultados gerados pelas políticas neoliberais aplicadas e o desgaste das elites políticas ligadas a essas medidas, abriram espaço para o surgimento e ascensão de novos atores às arenas de decisão (VILA, 2005; DEHEZA, 2007).

Assim, é razoável postular a relação entre o nível de estruturação dos sistemas partidários e o tipo de esquerda que identifica esses governos. Reiteramos, no entanto, que isso não significa dizer que os governos classificados como anti-sistêmicos foram os causadores da desestruturação dos sistemas partidários dos seus países. Todavia, na medida em que induziram o processo de fragmentação partidária, eles contribuíram para a aceleração de um processo que já estava em curso mesmo antes da eleição desses atores. Em outros termos, não podemos definir qual a direção causal desse fenômeno - se as esquerdas antissistêmicas causaram sistemas partidários não estruturados ou se o contrário -, mas as análises empíricas realizadas em cada caso têm revelado que diferentes esquerdas estão associadas a padrões distintos de estruturação do sistema partidário (PACHANO, 2010) e, por consequência, a patamares diferentes de estabilidade política.

Em várias ocasiões a debilidade dos sistemas partidários tem sido apontada como fator preponderante para o enraizamento dos vínculos entre eleitores e partidos (Mainwaring e Torcal, 2005). Como mostraremos na próxima seção, o indicador que utilizamos de estabilidade política das democracias está relacionado às condições de estruturação dos sistemas partidários. Esta associação pode ser evidenciada pela coincidência entre as taxas de estabilidade política verificadas nos países que apresentam sistemas partidários não estruturados. No entanto, cabe questionar se estabilidade política é um bom preditor da capacidade de governos promoverem desenvolvimento econômico e social. Em outros termos, seria a estabilidade política uma condição suficiente para a governança democrática?

12 Consenso de Washington é o termo que denota um conjunto de recomendações que economistas de instituições financeiras situadas em Washington D.C. nos Estados Unidos para conseguir alcançar o equilíbrio macroeconômico. Nos países da América Latina ganhou uma conotação de receituário liberal de regras e reformas econômicas que os Estados deveriam fazer para conseguir se adequar à realidade dos mercados globalizados. 


\section{PADRÕES DE GOVERNANÇA NA AMÉRICA DO SUL: ESTABILIDADE, UMA CONDIÇÃO SUFICIENTE OU NECESSÁRIA?}

Os presidencialismos latino-americanos são caracterizados por presidentes que possuem poderes de agenda ampliados, sobretudo do que diz respeito aos poderes legislativos (SHUGART e CAREY, 1992; O’DONNELL, 1994; LIJPHART, 1997). O excesso de poderes nas mãos do Presidente é entendido, nesse enquadramento, enquanto algo prejudicial para a democracia, podendo levar a situações de tentativa de usurpação dos poderes pelo Presidente e possibilitando a ele contornar ou mesmo ignorar o Congresso Nacional. Nessa perspectiva, o desempenho dos sistemas presidencialistas depende principalmente de fatores relacionados à força partidária do presidente, do sistema eleitoral e dos poderes legislativos do presidente definidos constitucionalmente (LINZ, 1994; MAINWARING, 1993; MAINWARING; SHUGART, 1997). A ideia é que presidentes com muitos poderes legislativos tenderiam a aumentar a instabilidade desse sistema, tendo em vista os incentivos gerados para que o executivo governe unilateralmente.

A despeito desses juízos apresentados acima, a verdade é que não existe nenhuma evidência substantiva de que presidentes com "super - poderes" escolham sempre agir unilateralmente (CHEIBUB et al, 2004). Tendo em vista que governos minoritários podem ser considerados uma tendência na América Latina (FIGUEIREDO et al ,2012) e baseado no pressuposto de que governos minoritários possuem dificuldade para formar maiorias, o argumento de que os presidentes sul americanos operam à revelia do poder legislativo poderia ser considerado razoável. No entanto, é justamente o amplo espectro das prerrogativas presidências e a possibilidade de contar com maiorias contextuais (STROM, 1990) $)^{13}$ que permite que executivos minoritários obtenham sucesso na arena legislativa. Dentro dessa perspectiva, a existência de um sistema partidário minimante estruturado torna-se ainda mais proeminente no processo de tomada de decisão e produção de estabilidade política.

Mainwaring e Scully (1995) destacam quatro condições para a estruturação dos sistemas partidários, a saber, i. competição interpartidária relativamente estável, ii. baixa volatilidade eleitoral, iii. legitimidade dos partidos na sociedade e, iv. a exigência de algum

\footnotetext{
13 De fato, muitos governos minoritários têm o apoio da maioria. Se os custos de se filiar a um determinado governo são mais altos que o retorno eleitoral, determinados partidos podem escolher apoiar apenas eventualmente o governo. Além disso, nas situações onde os partidos que não participam das coalizões de governo conseguem ter acesso e influência sobre as políticas públicas, não há razão - excluídas as motivações ideológicas - para compor o gabinete de forma permanente.
} 
nível de institucionalização dos partidos. Vejamos como essas condições variam substancialmente no cenário sul-americano.

Uma primeira evidência é que a competição eleitoral não tem contribuído para a estabilização dos sistemas partidários da América do Sul, ou seja, mesmo com eleições periódicas, a dinâmica recente da competição eleitoral sugere um sistema ainda fluído e não decantado. Como assevera Roberts (2012), tanto a volatilidade média dos pleitos legislativos quanto dos majoritários, aumentou na série temporal compreendida entre 1980 e 2000. No caso legislativo, a volatilidade eleitoral era de 17,4\% em 1980, 27,2\% em 1990 e atingiu seu ponto máximo no ano 2000, 31,1. Nos pleitos majoritários, em 1980 a taxa era de 19,6\%, passando para 22,8\% em 1990 e 26,7\% no ano 2000.

\section{GRÁFICO 1. CONFIANÇA NOS PARTIDOS POLÍTICOS, AMÉRICA DO SUL (1995-2010)14}

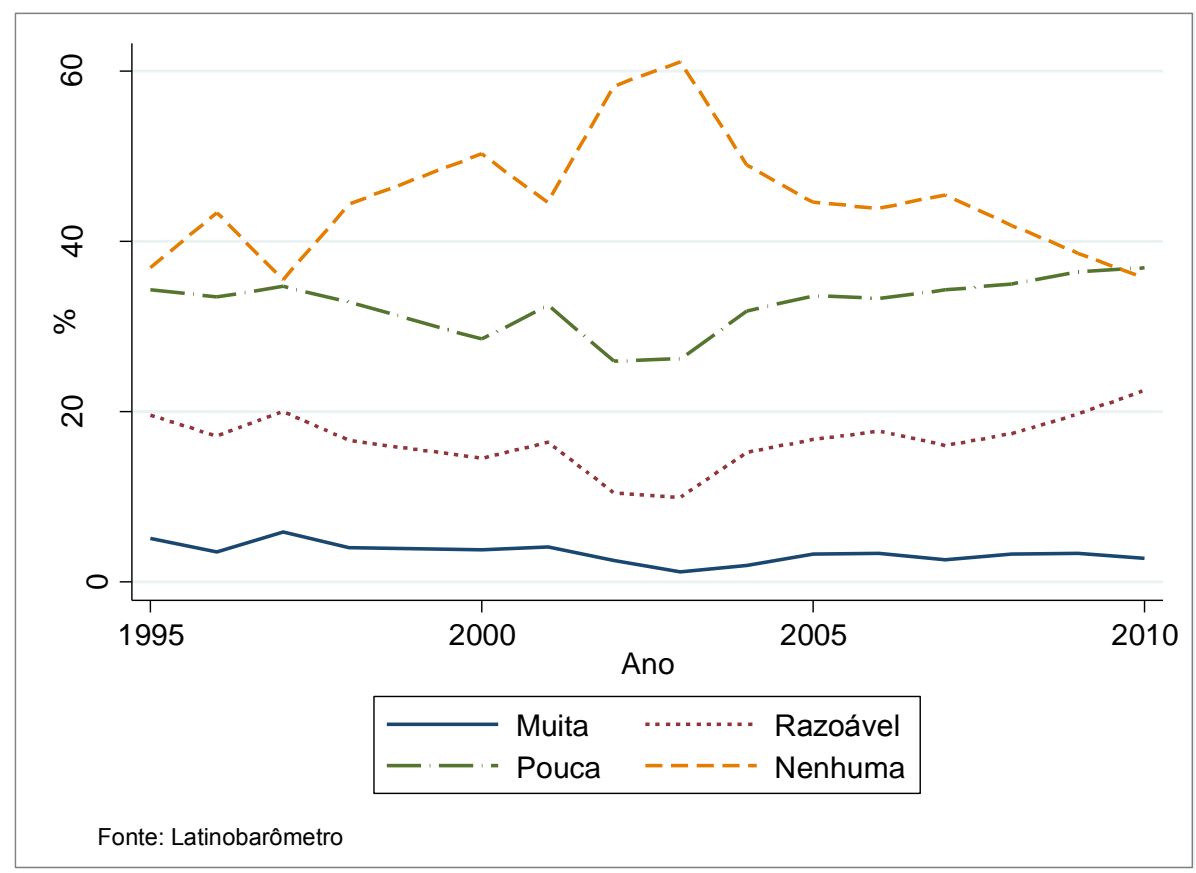

Em relação à legitimidade dos partidos, como é possível observar no gráfico 1, o nível de confiança nos partidos políticos na região é baixo, de acordo com os dados do Latinobarômetro entre 1995 e 2010. Quando agregamos as respostas daqueles que não tem nenhuma confiança e aqueles que depositam pouca confiança nos partidos políticos, a porcentagem chega a um número alarmante. Cerca de $70 \%$ dos cidadãos não tem nenhuma ou tem pouca confiança nos partidos políticos.

\footnotetext{
${ }^{14} \mathrm{~A}$ questão perguntada é: Por favor, mire esta tarjeta y dígame, para cada uno de los grupos, instituciones o personas mencionadas en la lista ¿cuánta confianza tiene usted en ellas: mucha(1), algo(2), poca(3) o ninguna(4) confianza en...? (Congresso Nacional, Poder Judicial, Partidos políticos, Forças armadas, Administração pública, governo local, Igreja, Tribunal eleitoral, Estado).
} 
Os dados evidenciam um quadro dramático sobre a confiança da população em partidos políticos na América do Sul. Observa-se, ainda, um ligeiro aumento daqueles que têm alguma confiança nos partidos políticos e uma discreta queda daqueles que não têm nenhuma confiança após a "maré rosa" que ocorreu nos anos 2000. Ainda assim, o dado é preocupante, uma vez que a dimensão cognitiva da confiança nos partidos políticos é um elemento fundamental para a consolidação do sistema partidário.

QUADRO 2. PODE HAVER DEMOCRACIA SEM PARTIDOS POLÍTICOS? MÉDIA ANUAL (2000-2010) LATINOBARÔMETRO ${ }^{15}$

\begin{tabular}{|lcc|}
\hline \multicolumn{1}{|c}{ País } & $\begin{array}{c}\text { Sem partidos } \\
\text { políticos não } \\
\text { pode haver } \\
\text { democracia }\end{array}$ & $\begin{array}{c}\text { A democracia } \\
\text { pode funcionar } \\
\text { sem partidos }\end{array}$ \\
Equador & 36,16 & 51,42 \\
Bolívia & 47,26 & 40,71 \\
Paraguai & 49,64 & 40,69 \\
Brasil & 45,22 & 38,54 \\
Chile & 56,46 & 30,53 \\
Venezuela & 62,14 & 29,52 \\
Argentina & 65,33 & 27,63 \\
Uruguai & 76,08 & 15,79 \\
\hline
\end{tabular}

Ainda de acordo com os dados do Latinobarômetro, analisamos a avaliação da relação entre democracia e partidos políticos (Quadro 2). Quando perguntados se pode haver democracia sem partidos políticos, $34,9 \%$ dos entrevistados responderam que sim, na média dos países analisados. Esse dado complementa o diagnóstico de crise de legitimidade dos partidos políticos na região.

Para além do fato de haver uma variação substantiva entre os países observados, nota-se que nos países onde o sistema partidário é não estruturado, a taxa de respondentes que considera que a democracia pode funcionar sem partidos é maior - Equador Bolívia, Paraguai, por exemplo, apresentam taxas elevadas de respostas nesse sentido -, ainda que seja necessário levar em consideração que nesses países não há o monopólio da representação ${ }^{16}$ dos partidos políticos.

15 Média das respostas nos anos 2000, 2001, 2002, 2005, 2006, 2008, 2009 e 2010. (exceto nos anos de 2003, 2004 e 2007 quando a pergunta não foi realizada)

${ }_{16}$ Nesses contextos (Equador, Bolívia, Paraguai, Venezuela, Peru) os candidatos não filiados a partidos políticos podem apresentar candidatura e serem votados. 
Além disso, fatos ocorridos recentemente no panorama político sul-americano colocam em xeque a estabilidade dos sistemas políticos da região. Após a terceira onda de redemocratização, nem todos os presidentes conseguiram concluir seus mandatos, ainda que as causas dessas interrupções sejam diversas (MARSTEINTREDET, 2014).

\section{QUADRO 3. RELAÇÃO DE PRESIDENTES QUE TIVERAM SEUS MANDATOS INTERROMPIDOS NAS DEMOCRACIAS DA AMÉRICA DO SUL}

\begin{tabular}{|c|c|c|}
\hline País & Nome do presidente & Ano \\
\hline \multirow[t]{3}{*}{ Argentina } & Raul Alfonsín & 1989 \\
\hline & Fernando de La Rúa & 2001 \\
\hline & Adolfo Rodríguez de Saá & 2002 \\
\hline \multirow[t]{2}{*}{ Bolívia } & Gonzalo Sánchez de Lozada & 2003 \\
\hline & Carlos Diego Mesa Gisbert & 2005 \\
\hline Brasil & Fernando Collor de Mello & 1992 \\
\hline \multirow[t]{3}{*}{ Equador } & Jamil Mahuad & 1997 \\
\hline & Abdalá Bucaram Ortiz ${ }^{17}$ & 2000 \\
\hline & Lucio Gutiérrez & 2005 \\
\hline \multirow[t]{2}{*}{ Paraguai } & Raul Cubas & 1999 \\
\hline & Fernando Lugo & 2012 \\
\hline Peru & Alberto Fujimori & 2000 \\
\hline Venezuela & Hugo Chávez & 2002 \\
\hline
\end{tabular}

Fonte: Elaboração própria

Collor em 1992 no Brasil, Fernando de La Rua na Argentina em 2001, e Alberto Fujimori no Peru em 2001, são exemplos de presidentes que não conseguiram concluir seus mandatos. Mais recentemente, houve a controversa destituição de Fernando Lugo no

\footnotetext{
${ }^{17}$ Abdala Buscaram foi deposto pelo congresso sob a alegação de "incapacidade mental".
} 
Paraguai em 2012 que, na visão dos analistas mais rigorosos, pode ser considerada um golpe de Estado (RECALDE, 2013).

No que diz respeito às condições gerais de estruturação dos sistemas partidários, dois argumentos tem sido aceitos com algum nível de consenso. O primeiro, defendido por Roberts e Wibbels (1999), associa volatilidade eleitoral à debilidade institucional e crises econômicas. O segundo, apresentado por Maiwaring e Scully $(1995,2008)$, defende uma associação entre sistemas partidários fracamente institucionalizados e o surgimento de governos populistas. De acordo com os autores, a incerteza produzida pelas altas taxas de volatilidade eleitoral abriria espaço para a consolidação de políticos outsiders de tendência autoritária. Sob esta perspectiva, com a exceção do Chile, Uruguai e Costa Rica, a América Latina seria uma soma de regimes competitivos com poucas possibilidades de produzir políticas públicas profícuas em seus resultados. Em outras palavras, em países politicamente instáveis os governos seriam incapazes de promover a melhoria das condições de vida da população.

Nós argumentamos que, no caso da América do Sul, apesar da estabilidade política ser uma condição necessária para a efetividade dos governos democráticos, esta não se configura como condição suficiente no que diz respeito a capacidade dessas democracias promoverem a melhoria das condições de vida de suas respectivas populações. Em outras palavras, é possível estimular o desenvolvimento econômico e social mesmo em contextos de baixa estabilidade. Antes de passarmos a exposição dos dados, discutiremos o conceito de governança e a forma como este conceito de associa a construção do nosso argumento.

\section{GOVERNANÇA DEMOCRÁTICA, ESTABILIDADE E INDICADORES ECONÔMICOS E SOCIAIS: DIMENSÕES EMPÍRICAS DAS DEMOCRACIAS SUL-AMERICANAS}

Governança pode ser definida como a capacidade de um governo democrático implementar políticas que contribuam para o desenvolvimento político, social e econômico do país (MAINWARING; SCULLY, 2009). Pode-se argumentar ainda que esse conceito tenha relação com a maneira pela qual o poder é exercido para gerenciar e promover recursos políticos, econômicos e sociais, ou com a capacidade de um determinado governo formular e executar suas políticas (KAUFMANN; MASTRUZZI, 2010). No limite, essas definições assentam-se na ideia de que regimes democráticos possuem padrões de gastos 
sociais superiores aos encontrados em regimes com elementos autoritários (BROWN; HUNTER, 1999), bem como melhor provisão de serviços públicos (LAKE; BAUM, 2001). No caso específico da América do Sul, parte da literatura tem utilizado as debilidades institucionais dessas democracias para inferir uma completa incapacidade desses governos para prover qualidade de vida as suas populações.

Assim, sistemas politicamente instáveis como a Venezuela, Equador e Bolívia, não seriam casos típicos de governança democrática, sentenciando estas nações a toda sorte de crises, sejam elas de ordem econômica, política ou social. Assumindo essa definição de governança e a relação entre este conceito e as condições de estruturação dos sistemas partidários, devemos presumir que todas as democracias sulamericanas pouco estáveis são incapazes de implementar boas políticas para seus cidadãos. No entanto, apesar de desejável, estabilidade política não é uma condição sufiente para a promoção de desenvolvimento econômico e social.

A fim de testar nosso argumento, utilizamos um indicador de estabilidade política e um indicador de governança, contrastando essas medidas com indicadores de desenvolvimento econômico e social. Nosso indicador de estabilidade política classifica todos os presidentes analisados em relação a estabilidade política de seus mandatos. $\mathrm{O}$ indicador de governaça classifica os presidentes analisados quanto a sua capaciade de implementar políticas públicas. Utilizamos indicadores de desenvolvimento econômico (PIB percapita) e desenvolvimento social (porcentagem do PIB com gasto social, taxa de desempego, porcentagem da população vivendo com menos de dois dólares por dia e o índice de desenvolvimento humano).O obejtivo é analisar se estes indicadores acampanham a medida de estabilidade. Ou seja, analisamos se os países classificados como pouco estáveis, de fato, foram incapazes de proporcionar ganhos em qualidade de vida para seus cidadãos ao longo da série temporal analisada ${ }^{18}$.

\footnotetext{
18 PIB per capita - 1990-2010

$\%$ do PIB em Gasto Social - 1990-2010

\% da População vivendo com menos de 2 dólares por dia -1990-2010

IDH - 1980-2010

Taxa de Desemprego - 1990-2013
} 


\section{GRÁFICO 2. ÍNDICE DE ESTABILIDADE POLÍTICA DOS PRESIDENTES DE \\ ESQUERDA NA AMÉRICA DO SUL}

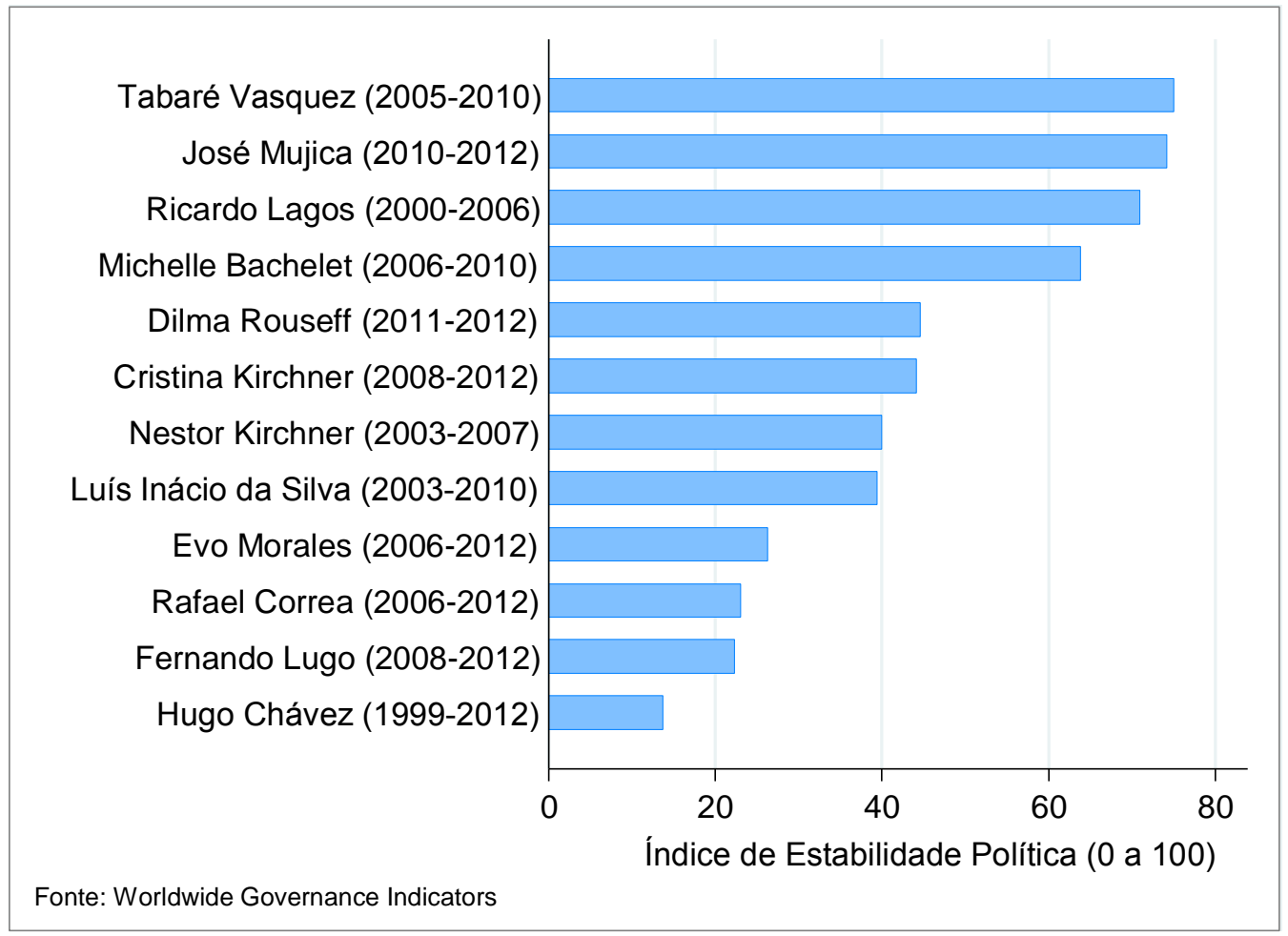

$\mathrm{O}$ indicador de estabilidade ${ }^{19}$ política é constituído a partir da opinião de especialistas consultados em cada país, refletindo a média ponderada das impressões acerca da estabilidade política em cada caso. As barras do gráfico refletem a média de estabilidade de todos os anos, de cada mandato analisado.

A análise do gráfico 2 sugere que, em conformidade com os dois eixos analíticos adotados nesse trabalho, os países com sistemas partidários não estruturados e governos da esquerda antissistêmica apresentam as menores médias de estabilidade política entre os sistemas políticos sul-americanos analisados. Em outra direção, os países com sistemas partidários estruturados e com governos de esquerda do tipo sistêmica são mais estáveis. Em outras

\footnotetext{
${ }^{19} \mathrm{O}$ Worldwide Governance Indicators (WGI) é um projeto do Banco Mundial que visa agregar indicadores de governança. O WGI compila e sistematiza informações de 31 fontes de dados existentes que informam os pontos de vista e experiências de cidadãos, empresários e especialistas nas áreas públicas, privadas e terceiro setor de todo o mundo, sobre a qualidadede vários aspectos de governança. É composto por seis dimensões, a saber, voz e accountability, estabilidade política e ausência de violência, efetividade governamental, qualidade regulatória, Estado de direito e controle da corrupção. Esses dados apresentados no gráfico acima se referem a segunda dimensão do indicador: estabilidade política e ausência de violência, a seguir apresentamos os dados referentes à dimensão da efetividade governamental. $O$ conceito de governança utilizado é o seguinte: "tradições e instituições pelas quais a autoridade de um país é exercida. Isso incluio processo pelos quais governos são selecionados, monitorados e substituídos; a capacidade do governo para formular e implementar com eficáciapolíticas sólidas; e o respeitodos cidadãos e doEstado para com as instituições que governam as interaçõeseconômicas e sociais entre eles". Nossos dados se referem, respectivamente, a segunda e terceira dimensão do indicador: estabilidade política e ausência de violência e efetividade governamental.
} 
palavras, os dados sugerem uma correspondência entre maior estabilidade política por um lado e governos de esquerda e sistemas partidários estruturados por outro.

\section{GRÁFICO 3. ÍNDICE DE GOVERNANÇA E EFETIVIDADE DOS PRESIDENTES DE ESQUERDA NA AMÉRICA DO SUL}

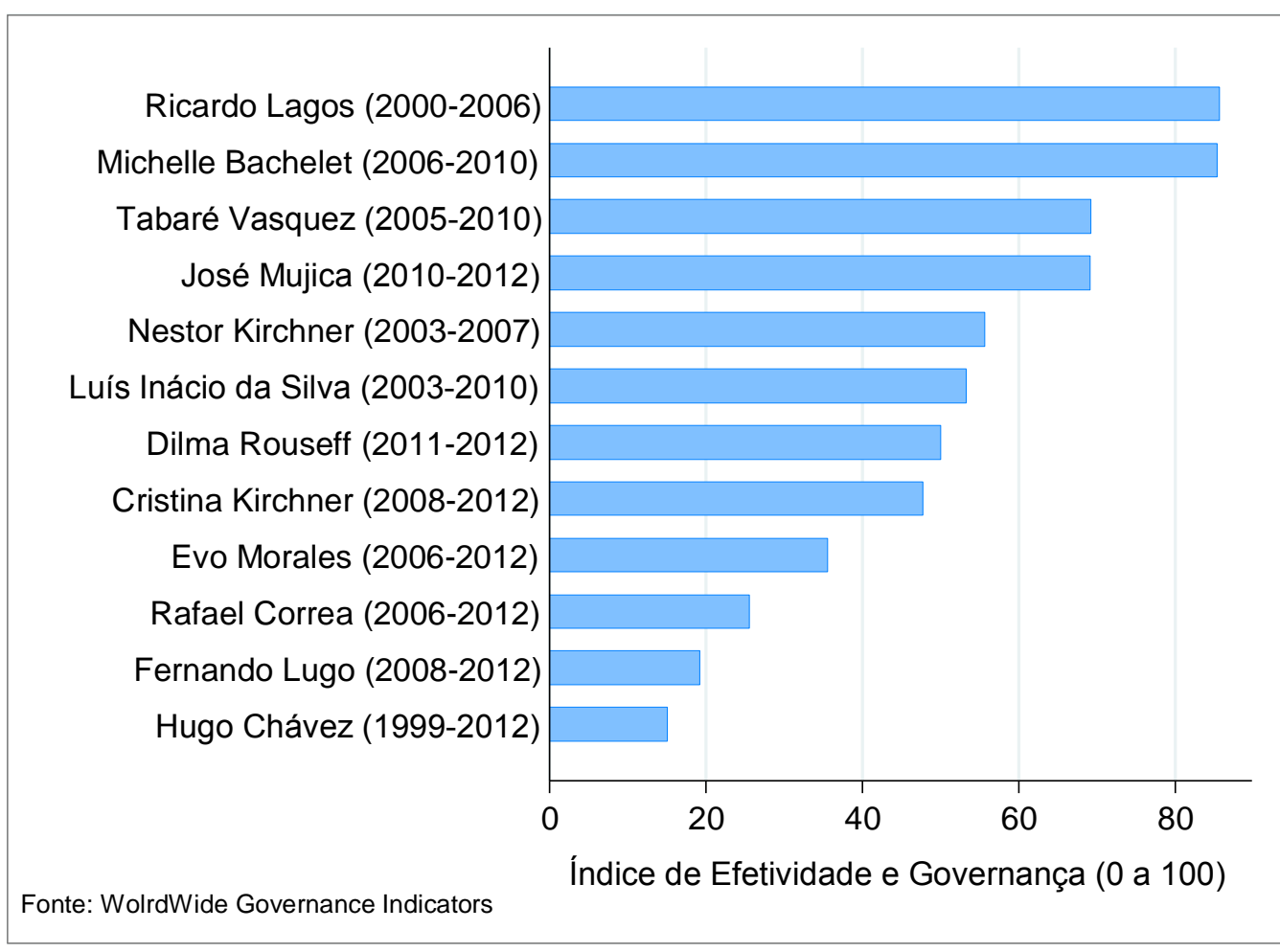

O segundo indicador diz respeito à capacidade efetiva dos governos para formular e implementar políticas públicas. Trata-se da percepção de especialistas no que tange a qualidade de formulação e execução dos serviços públicos, bem como a credibilidade do governo em relação à prestação dos serviços em geral. Do mesmo modo, foi feita uma média para os anos de governo de cada mandato analisado.

O gráfico 3 revela que a percepção da efetividade do governo é menor nas democracias onde os sistemas partidários são não-estruturados e onde as esquerdas antissistêmicas estão no poder. O teste de Pearson $^{20}$ realizado entre os dois indicadores apresentou um alto valor de correlação de 0.978. Isso indica que, à medida que cresce a percepção de estabilidade, cresce também a percepção de efetividade e governança. Tendo em vista que nas democracias investigadas os contextos nos quais os sistemas partidários apresentam maior nível de estruturação são também aquelesem que existe maior percepção

\footnotetext{
${ }^{20} \mathrm{O}$ teste de correlação de Pearson varia entre 0 e 1 e mede a associação (positiva ou negativa) entre duas
} variáveis. Quanto mais próximo de 1 maior a associação entre as duas variáveis. 
de estabilidade, é possível inferir que sistemas partidários não estruturados estão associados com baixos níveis de percepção de estabilidade. É dizer que, nos casos em que as esquerdas governistas possuem uma plataforma de governo antissistêmica, a percepção de efetividade das políticas pelo governo é menor.

\section{TABELA 1. COMPARAÇÃO DA PERCEPÇÃO DE ESTABILIDADE ENTRE O GRUPO DOS PAÍSES COM SISTEMAS PARTIDÁRIOS ESTRUTURADOS E OS PAÍSES COM SISTEMA PARTIDÁRIO NÃO ESTRUTURADO}

\begin{tabular}{lcc}
\hline & \multicolumn{2}{c}{ Tipo de Sistema Partidário } \\
\hline Países & & \\
\hline Média de Estabilidade & 64.69 & 28.28 \\
& & \\
Diferença de Médias & $36.40 * * *$ \\
& $(8.087)$ \\
& Erro Padrão robusto entre parênteses \\
\hline & $* * * \mathrm{p}<0.01, * * \mathrm{p}<0.05, * \mathrm{p}<0.1$ \\
\hline
\end{tabular}

Fonte: elaboração própria

De forma complementar, na tabela 1 , realizamos o teste de diferença de médias entre a percepção de estabilidade política nos países com sistema partidário estruturado e nos países com sistema partidário não estruturado. A diferença positiva e estatisticamente significante (0.01) na escala do nosso índice de estabilidade política revela que, de fato, a não estruturação dos sistemas partidários está relacionada com baixos níveis de estabilidade nos países investigados. A média de estabilidade política nos países com sistema partidário estruturado é 36.40 pontos maior.

Assim, à luz dos argumentos de Mainwaring e Scully (2008), governos como Hugo Chávez (Venezuela), Fernando Lugo (Paraguai), Rafael Correa (Equador) e Evo Morales (Bolívia), não seriam capazes de promover políticas públicas de grande impacto. $\mathrm{Ou}$ seja, esses governos não deveriam ser capazes de promover desenvolvimento econômico e social aos seus cidadãos, quando comparados aos governos Sul americanos com média estabilidade - Brasil (Lula e Dilma) e Argentina (Nestor e Cristina Kirchner) e alta estabilidade - Chile (Lagos e Bachelet) e Uruguai (Vásquez e Mujica).

Observando o conjunto de dados, uma primeira constatação a ser feita é que os três grupos (alta, média e baixa estabilidade) de países melhoraram seus indicadores econômicos e sociais nas últimas três décadas. O gráfico 4 evidencia que mesmo nos países pouco estáveis os governos de esquerdas foram capazes de garantir crescimento econômico. 
GRÁFICO 4. PIB PER CAPITA - AMÉRICA DO SUL (1990-2010)

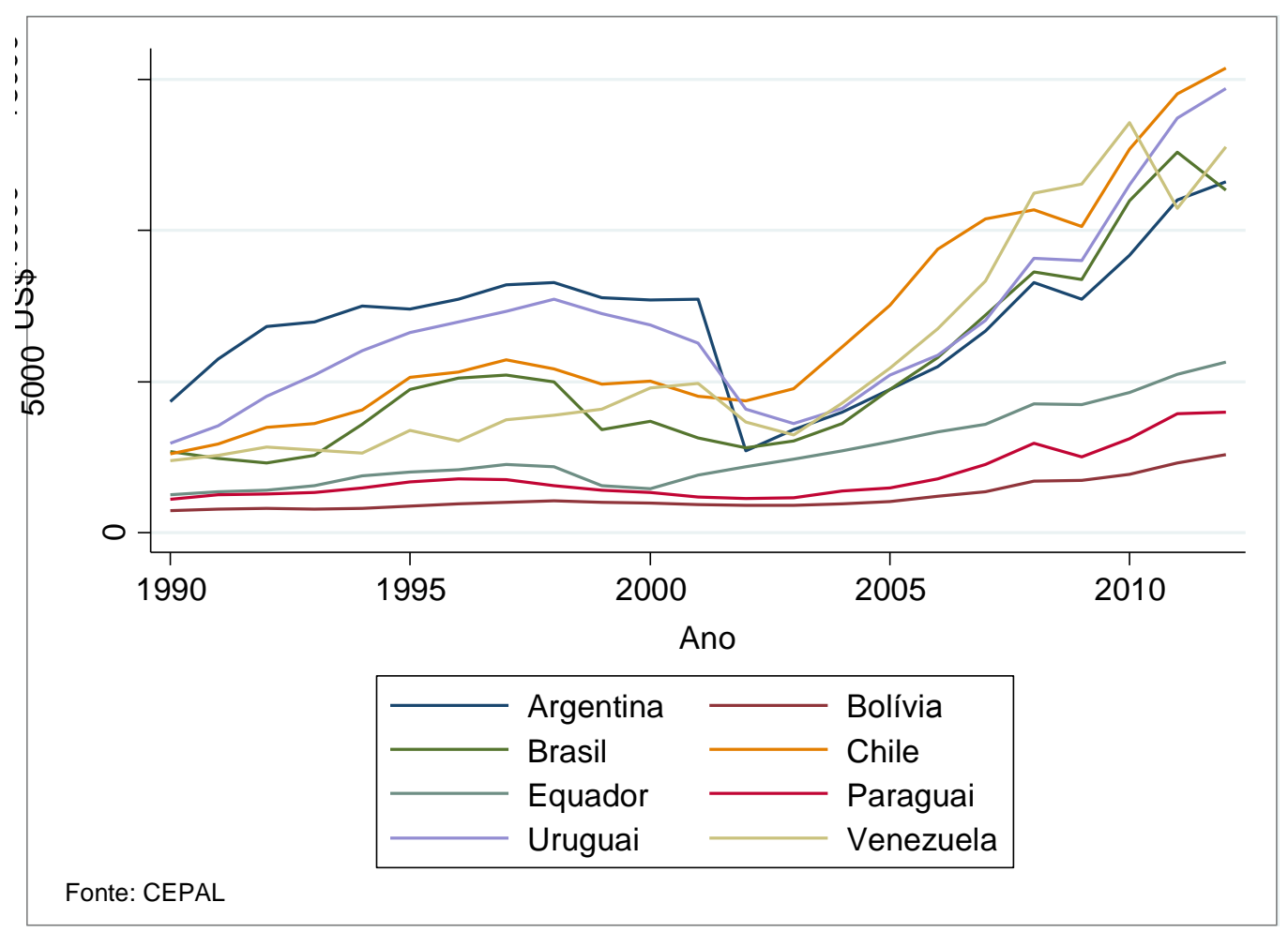

Todavia, é sabido que crescimento econômico, quando não acompanhado de redistribuição de renda e/ou políticas voltadas para investimentos na área social, não significa melhoria na qualidade de vida dos extratos mais vulneráveis da população. Pensando nisso, apresentamos abaixo um conjunto de indicadores de desenvolvimento social. O primeiro deles mostra a porcentagem do PIB de cada país alocado em gasto social.

O gráfico 5 revela uma tendência de crescimento de investimentos dos governos de esquerda na área social. Isso significa que o crescimento da economia tem sido acompanhado de esforços que objetivam diminuir as condições de desigualdade e pobreza que apresentam, em graus diferentes, os países analisados. No entanto, faz-se necessário ponderar se tais esforços têm alcançado algum êxito. No gráfico 6 apresentamos dados sobre a porcentagem da população de cada um dos países vivendo com menos de dois dólares por dia. 
GRÁFICO 5. \% DO PIB ALOCADO EM GASTO SOCIAL - AMÉRICA DO SUL (1990-2010)

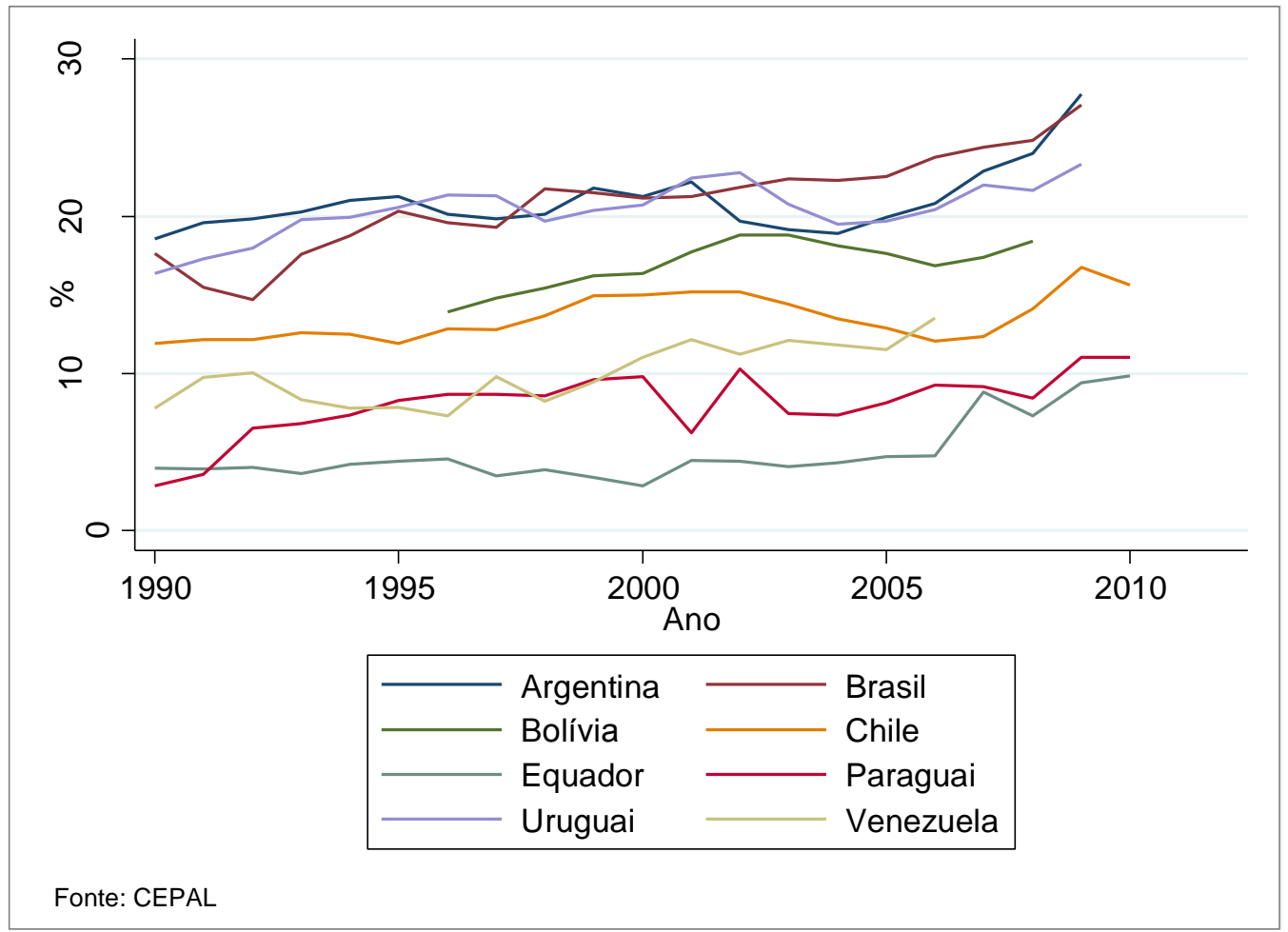

Nos três conjuntos de países (alta, média e baixa estabilidade política) a porcentagem da população vivendo com menos de dois dólares por dia apresenta uma tendência de queda. Além disso, mesmo nos casos onde essa tendência é observada desde o início da série temporal utilizada, verifica-se uma coincidência da ascensão dos governos de esquerda e melhora desse indicador. Nós acreditamos que esses números podem ser lidos como o resultado da política de aumento do gasto social e redução da pobreza, implementadas pelos governos de esquerda na América do Sul. A tendência de melhoria persistente no Índice de Desenvolvimento Humano (gráfico 8) reforça este argumento 
GRÁFICO 6. \% DA POPULAÇÃO VIVENDO COM MENOS DE DOIS DÓLARES POR DIA - AMÉRICA DO SUL (1990-2010)

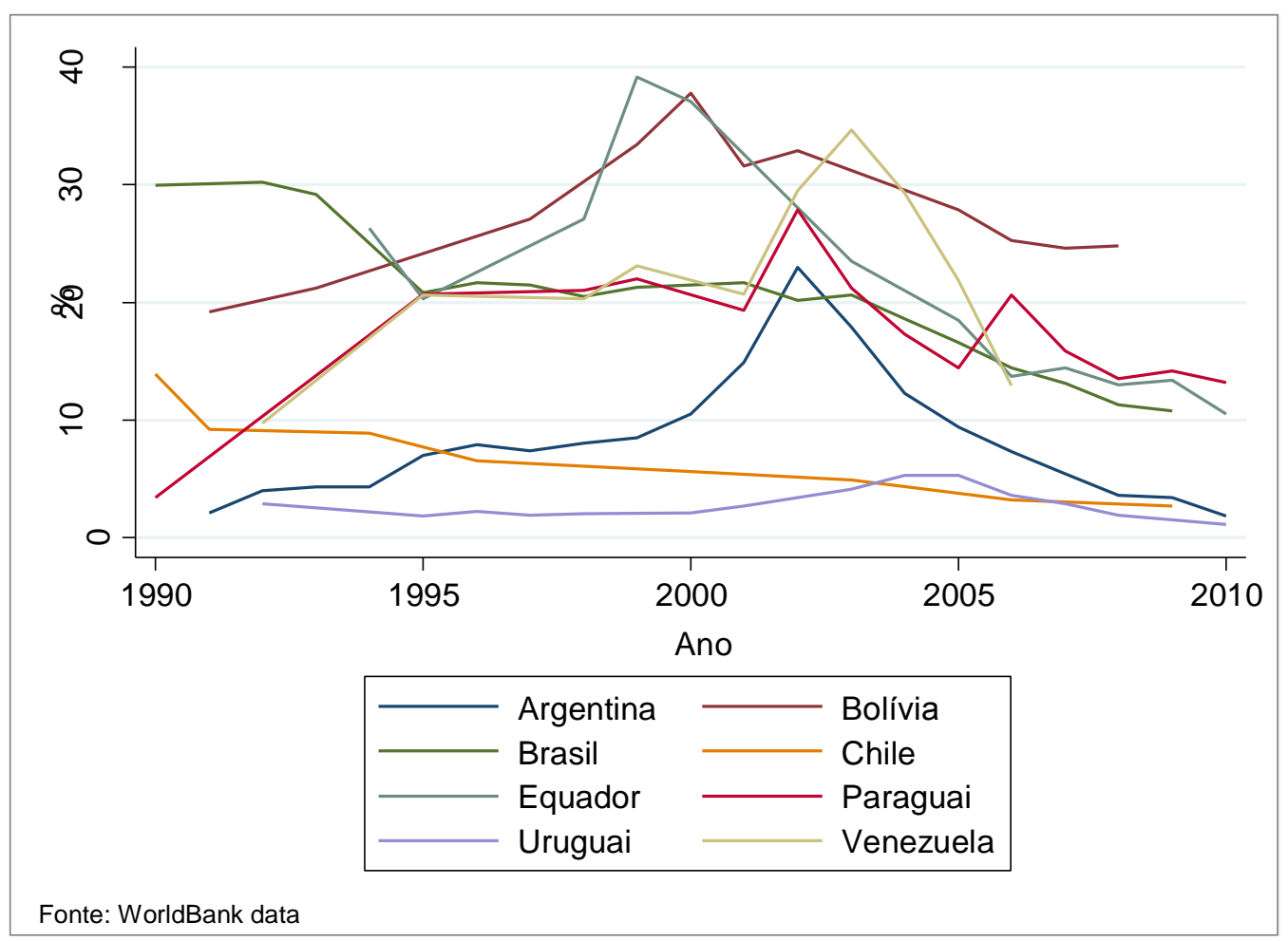

GRÁFICO 7. TENDÊNCIA DO ÍNDICE DE DESENVOLVIMENTO HUMANO AMÉRICA DO SUL (1980-2010)

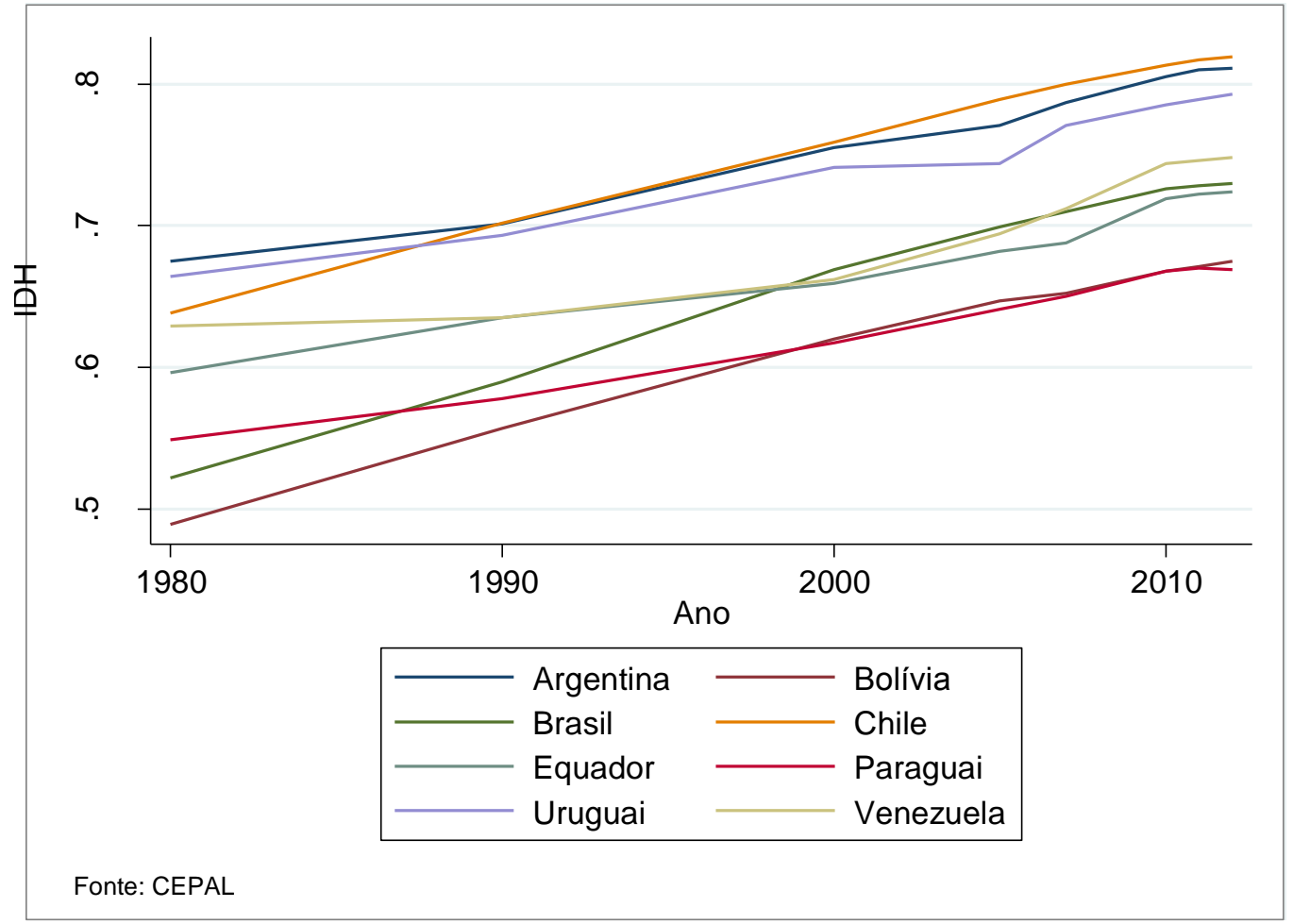


Ainda que a tendência de melhoria desse indicador tenha se iniciado antes da chegada dos governos de esquerda no poder, esses governantes têm sido capazes de manter e, em alguns casos, maximizar essa tendência. Por fim, apresentamos dados das taxas de desemprego (gráfico 8) nos países analisados da América do Sul. Para muitos dos países analisados, as taxas de desemprego verificadas durante os governos de esquerda são as menores da série. Isso acontece tanto em países com alta e média estabilidade (Chile, Uruguai e Argentina), quanto em países com baixa estabilidade (Bolívia e Equador).

GRÁFICO 8: TAXA DE DESEMPREGO - AMÉRICA DO SUL (1990-2013)

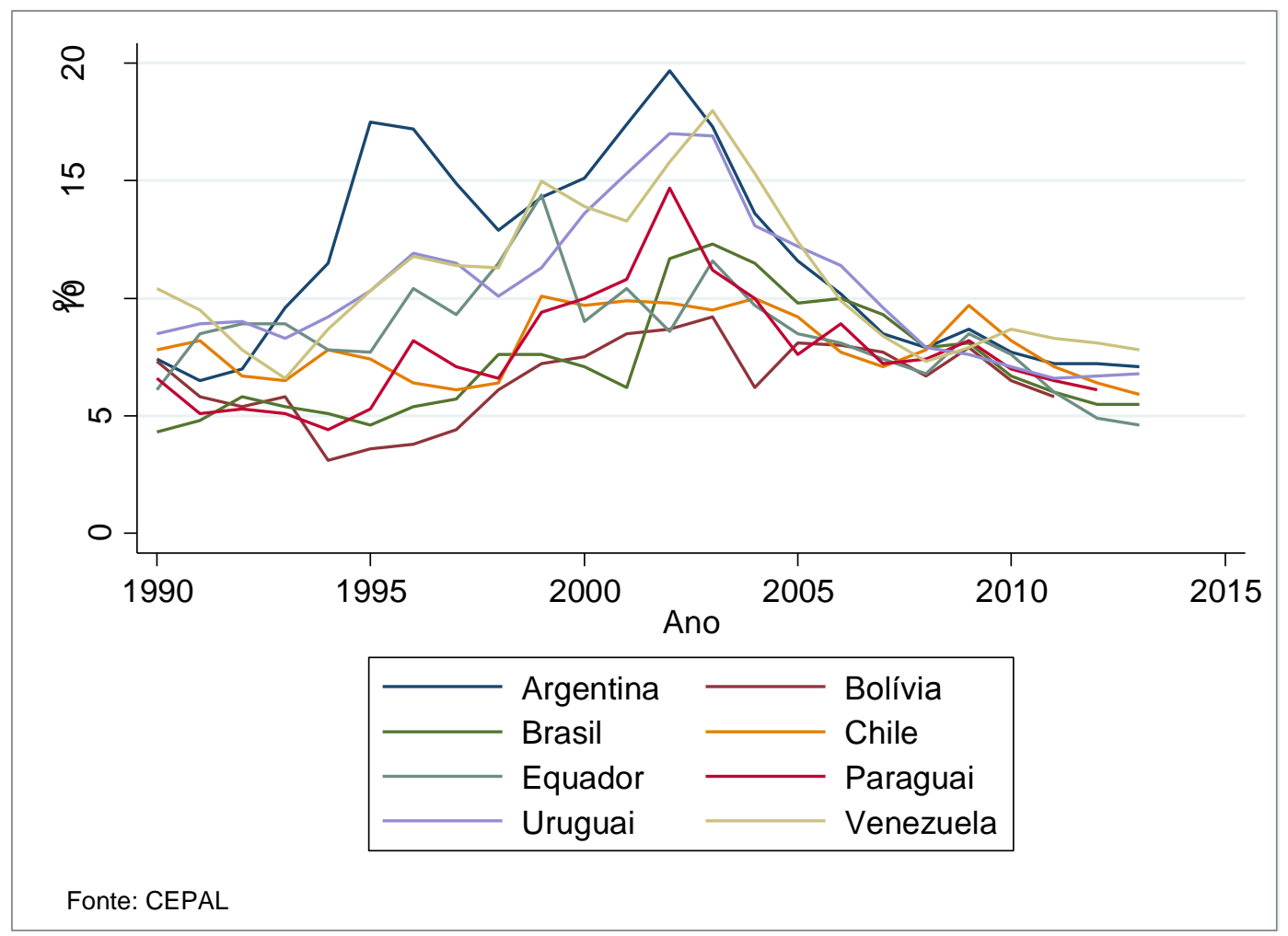

Nos três grupos existe uma tendência de crescimento econômico e aumento dos gastos sociais. Além disso, em quase todos os casos, no que diz respeito ao gasto social, a melhoria nas taxas de pobreza e a redução do desemprego, o ponto de inflexão é a chegada das esquerdas no poder. Apesar da percepção de estabilidade política variar em função do nível de estruturação dos sistemas partidários e do tipo de esquerda que cada presidente representa, mesmo nos países onde a baixa estabilidade política é uma regra, estes governos têm conseguido garantir um crescimento acima dos períodos anteriores, acompanhado de uma política de investimentos na área social. 


\section{CONCLUSÕES}

Duas principais conclusões podem ser retiradas da análise aqui proposta. Em primeiro lugar, a percepção da estabilidade política varia em função do nível de estruturação dos sistemas partidários e do tipo de esquerda que chegou ao poder em cada país. Nos países com sistemas partidários estruturados e com esquerdas do tipo sistêmica, há uma maior percepção de estabilidade política. Em outra direção, países com sistemas partidários do tipo não estruturado e com esquerdas do tipo antissistêmica apresentam menor percepção de estabilidade. Vale ressaltar que a desestruturação dos sistemas partidários é anterior à chegada ao poder das esquerdas antissistêmicas, porém a sua agenda política acabou por agravar essa crise e comprometer as já abaladas arenas de contestação democráticas existentes nesses sistemas políticos.

Em segundo lugar, argumentamos que a estabilidade política não é uma condição suficiente para a governança democrática, pelo menos nos termos utilizados no presente trabalho. No contexto sul-americano, mesmo nos países de baixa estabilidade, os governos de esquerda tem sido hábeis no que diz respeito à implementação de políticas que melhorem as condições de vida da população de baixa renda. Os dados sobre desenvolvimento econômico e social vão ao encontro desse argumento.

Há casos mais dramáticos de comprometimento da democracia e de transformação desses regimes políticos. Elementos de personalismo e neopopulismo se mesclaram à liderança desses presidentes identificados com plataformas antissistêmicas e trouxeram consequências dramáticas para o jogo democrático nesses países. Faz-se necessário considerar ainda a heterogeneidade das formas democráticas assumidas nessa nova conformação política na região da América do Sul. Propostas de reforma social, no sentido social-democrata, em alguns casos convivem com experiências de democracia social radical, com impactos significativos para a qualidade e para a estabilidade dos sistemas políticos da região.

Por fim, cabe considerar que as agendas políticas dos presidentes eleitos trouxeram consigo novos elementos de inclusão política e social de grupos excluídos, inclusive de grupos indígenas, como nos casos de Equador e Bolívia. Nesses países as plataformas propuseram a refundação das bases de legitimidade do Estado, mas trouxeram consigo patamares razoáveis de inclusão econômica e política. Essa dimensão paradoxal da governança democrática deve ser investigada de forma a se compreender como as arenas de contestação democráticas estão se conformando a partir da chegada dessas novas esquerdas ao poder. 


\section{REFERÊNCIAS BIBLIOGRÁFICAS}

ALTMAN, D (2010). Direct Democracy Worldwide. Cambridge University Press.

BELÉM LOPES, D. (2013). A economia política da década bolivariana: instituições, sociedade e desempenho dos governos em Bolívia, Equador e Venezuela (1999-2008). Revista Estudos Políticos, v. 6, p. 261-277, 2013.

BROWN D; HUNTER, W. (1999). Democracy and social Spending in Latin America, 1980-92. American Political Science Review. Vol, 93. No. 4. December.

BUXTON, J (2009). "Venezula: The political evolution of Bolivarianism". In. Reclaming Latin America: Experiments in Radical Social Democracy, Ed. Geraldine Lievesley and Steve Ludlam. London: Zed Books, 57-74.

CASTANEDA, J (2006). "Latin America's Left Turn." Foreign Affairs. nº 1 May.

CHEIBUB, J.A; PRZEWORSKI, A; SAIEGH, S (2004). Government Coalitions under Parliamentarism and Presidentialism. British Journal of Political Science, 34: 565-587, 2004.

DEHEZA, G (2007). Reforma Estatal y Construcción del Poder. Revista de Ciência Política, pp. $43,57$.

DIAMOND, L(2002). “Thinking about hybrid regimes". Elections Without Democracy. Journal of Democracy Vol. 13, number 2, April.

GEREFFI, G; HARTLYN, J; GARRETON, M.A; CAVAROZZI, M; CLEAVES, P (2007). América latina no século XXI: em direção a uma nova matriz sociopolítica. Editora FGV.

FIGUEIREDO, A; CANELLO, J; VIEIRA, M.(2012) “Governos Minoritários no Presidencialismo Latino Americano: Determinantes Institucionais e Políticos". Dados, vol 55(4), pp 839-875.

HUBER, E; STEPHENS, J.D(2012). Democracy and the Left: Social Policy and Inequality in Latin America. Chicago: University of Chicago Press, 2012.

KAUFMANN, K; MASTRUZZI, R (2010). The Worldwide Governance Indicators: Methodology and Analytical Issues. Word Bank Indicators.

LAKE, D; BAUM, M (2001). The Invisible Hand of Democracy Political Control and the Provision of Public Services. Comparative Political Studies, August. 34: 587-621.

LANZARO, J (2007). "Gobiernos de izquierda en América Latina: entre el populismo y la social democracia - Una tipología para avanzar en el análisis comparado". Análise de Conjuntura Observatório Político Sul-Americano OPSA - IUPERJ/UCAM, n.12, dez.

LATINOBARÔMETRO. Dados dos anos de 1995, 1996, 1997, 1998, 1999, 2000, 2001, 2002, 2003, 2004, 2005, 2006, 2007, 2008, 2009, 2010. Disponível em: http://www.latinobarometro.org/latContents.jsp Acesso em 26/05/2014. 
LA TORRE, C (2013). In the Name of the People: Democratization, Popular Organizations, and Populism in Venezuela, Bolivia, and Ecuador. European Review of Latin American and Caribbean Studies Revista Europea de Estudios Latinoamericanos y del Caribe. No. 95, October, pp. 27-48.

LEVITSKY, S; WAY, L (2002) “The Rise of Competitive Authoritarianism”. Elections Without Democracy. Journal of Democracy. Vol. 13, number 2, April.

LIEVESLEY,G; LUDLAM, S (2009). Reclaiming Latin America: experiments in radical social democracy. Zeb Books Ltd, London, New York.

LIJPHART, A (1997). Patterns of democracy. New Haven: Yale University Press.

LINZ, J (1994). "Presidential or Parliamentary Democracy: Does it Make a Difference?" IN: LINZ, J. and VALENZUELA, A. (eds.). The Failure of Presidential Democracy. Baltimore: Johns Hopkins. University Press.

MADRID, R (2010). Leftist Governments in Latin America: Successes and Shortcomings. New York: Cambridge University Press, 2010, xv + 216 pp. (Co-edited with Kurt Weyland and Wendy Hunter).

MAINWARING, S; SHUGART, M (1997). Presidentialism and Democracy in Latin America. Cambridge Univeristy Press.

MAINWARING, S (1993). "Presidentialism and Multipartism. The Difficult Combination". In: Comparative Political Studies N. 26.

MAINWARING, S; SCULLY, T (1995). Building democratic institutions: Party systems in Latin America. Stanford: Stanford University Press.

MAINWARING, S; SCULLY, T (2008) "Latin America: Eight Lessons for Governance". Journal of Democracy. July, volume 19, issue, 3, p.112-127.

MAINWARING, S; SCULLY, T (2009). Democratic Governance in Latin America. Stanford University Press.

MAINWARING, Scott and TORCAL, Mariano. Teoria e institucionalização dos sistemas partidários após a terceira onda de democratização. Opin. Publica [online]. 2005, vol.11, n.2 [cited 2015-04-06], pp. 249-286 . Available from: $<$ http:/ /www.scielo.br/scielo.php?script=sci_arttext\&pid=S0104$62762005000200001 \& \operatorname{lng}=$ en\&nrm=iso $>$.

MARTEINTREDET, L. (2014)."Explaining variation of executive instability in presidential regimes: Presidential interruptions in Latin America". International Political Science Review, vol 35(2), pp 173-194, 2014.

MELO, C. R. F. (2015). Os partidos e as democracias: passado, presente e futuro. Melo (no prelo).

MITRE, A. F. (2009). As peregrinações de um conceito: populismo na América Latina. Cadernos de História, Belo Horizonte, v. 10, n. 13, p. 9-23, dez. 2009. ISSN 2237-8871. 
Disponível

em:

< http://periodicos.pucminas.br/index.php/cadernoshistoria/article/view/941>. Acesso em: 06 Abr. 2015. doi:10.5752/941.

MORLINO, L (2008) “Hybrid Regimes or Regimes in Transition?” FRIDE, Working Paper 70, september.

NUNES, F (2014) The Left Variance: How Electoral Mechanisms Shape Leftist Presidential Behavior in Latin America. RIEL - Revista Ibero-Americana de Estudos Legislativos: N.1,Mar, Rio De Janeiro: FGV. (25-34).

O'DONNELL, G (1994). Delegative Democracy. Journal of Democracy - Volume 5, Number 1, January, pp. 55-69.

PACHANO, S (2010). Ecuador: El nuevo sistema político en funcionamiento. Revista de Ciencia Politica, v 30, No 2, p $297-317$.

PIKETTY, T (2014). O Capital no Século XXI. Rio de Janeiro: Intrínseca.

RECALDE, L(2013). Paraguay: interrupción al proceso de consolidaciónde la democracia. Revista de Ciencia Política, volumen 33, n 1, p 303-324.

ROBERTS, K (2012). Market Reform, Programmatic (De)alignment, and Party System Stability in Latin America. Comparative Political Studies XX(X) 1-31 published online 9 September.

ROBERTS, K; WIBBELS, E. (1999). Party systems and electoral volatility in Latin America: A test of economic, institutional, and structural explanations. American Political Science Review, 93, 575-590.

ROHTER, L. (2005) With New Chief, Uruguay Veers Left, in a Latin Pattern. NY Times, International. Disponível em: http://www.nytimes.com/2005/03/01/international/americas/01uruguay.html? r $r=0$ Acesso em 06/04/2015.

SELIGSON, M. (2007) The Rise Of Populism And The Left In Latin America. Journal of Democracy. Volume 18, Number 3 July 20.

SHUGART M. and CAREY, J. (1992). Presidents and Assemblies. Cambridge: Cambridge University Press.

STROM, K. (1990). Minority government and majority rule. Cambridge University Press, 1990.

VILLA, R. (2005). Venezuela: political changes in the Chávez era. Estudos Avançados 19 (55).

WORLDWIDE GOVERNANCE INDICATORS (WGI). World Bank. Disponível em: http://info.worldbank.org/governance/wgi/index.aspx\#home 